\title{
Evaluation of Heavy Metals of Lead, Nickel, Cadmium, Vanadium and Some Chemical Parameters in Surface Soils of the City of Khorramabad
}

\author{
M. Karimizadeh ${ }^{1,2}$, K. Payandeh ${ }^{3 *}$ \\ ${ }^{1}$ Department of Environmental Engineering, Khuzestan Science and Research Branch, Islamic Azad University, Ahvaz, Iran \\ ${ }^{2}$ Department of Environmental Engineering, Ahvaz Branch, Islamic Azad University, Ahvaz, Iran \\ ${ }^{3}$ Department of Soil Science, Ahvaz Branch, Islamic Azad University, Ahvaz, Iran
}

\section{PAPER I NFO}

\section{Paperhistory:}

Received 29 October 2020

Accepted in revised form 10 April 2021

\section{Keywords:}

Electrical conductivity

Heavy metals

Khorramabad

Soil pollution

Toxicity

\section{$\begin{array}{lllllllll}A & B & S & T & R & A & C & T\end{array}$}

This study was conducted in 2017 with the aim of determining the distribution of heavy metals lead, nickel, cadmium, vanadium and the parameters of acidity, electrical conductivity and organic matter in the surface soils of the city of Khorramabad. Sampling was performed monthly from 12 stations and was repeated 3 times in the autumn. The highest amount of cadmium was observed in the soil samples of industrial areas of the city in the two sampling periods of October and December to be $7 \mathrm{ppm}$. A comparison of the mean measured values of heavy elements showed that the highest average amounts of heavy elements are in industrial areas and the lowest in residential areas. The lowest amount was measured in $8^{\text {th }}$ and $11^{\text {th }}$ stations at $2 \mathrm{ppm}$. The highest amount of lead in the $6^{\text {th }}$ station, a bustling area, was measured to be $22 \mathrm{ppm}$. The average nickel in industrial areas was higher than other areas. In industrial area, during the sampling period of October, its amount was determined to be $58 \mathrm{mg} / \mathrm{kg}$. The highest amount of vanadium was recorded in staion 9 at $52 \mathrm{mg} / \mathrm{kg}$. Lead has a significant correlation with nickel, cadmium and soil acidity. This correlation is $0.01 \%$ for acidity and cadmium variables and $0.03 \%$ for nickel. Nickel has a significant correlation with cadmium and vanadium at the level of $0.01 \%$. The results indicate that the surface soil of the city of Khorramabad is not contaminated with the studied metals. In general, the results showed that both human and natural factorsare always involved in the distribution and concentration of heavy metals.

doi: 10.5829/ijee.2021.12.02.05

\section{INTRODUCTION}

Soil pollution due to heavy metal pollution is one of the most serious environmental threats to soil quality [1,2]. The severity of this problem has increased in industrialized countries in recent decades [3]. Recent developments in the global economy have led to an increase in heavy metals in soil, both in type and amount [4]. In particular, the contamination of agricultural soils due to the widespread use of chemical fertilizers, natural pesticides, animal manures, irrigation with sewage and sewage sludge, solid wastes, chemical compounds and atmospheric sediments in an effort to increase crop yield $[5,6]$.
When analyzing different types of soil contaminants, heavy metals are particularly dangerous due to their stability and toxicity [7]. Soil acts as a reservoir for heavy metals through adsorption, displacement, and mobility reactions [8]. Due to its proximity to humans, the accumulation of chemical compounds in urban soils is of great concern [9]. There are two main sources of heavy metals in the soil. The first one is naturall, which comes from the concentration of heavy metals in the the parent rocks. The second one, anthropogenic contaminants, includes agrochemical organic matter, animal manure, mineral fertilizers, sewage sludge, and industrial wastes and effluents $[10,11]$.

\footnotetext{
*Corresponding Author Email: Payandeh426@gmail.com (K. Payandeh)
} 
Heavy metals have negative effects on human health because of their stability and toxicity [12] and may be transmitted to the human body through ingestion, inhalation and skin contact or through the food chain [13]. Although dust inhalation is primarily hazardous to human health, heavy metal dust is also concentrated in the soil and with the migration of metals may become a secondary environmental hazard in terms of agricultural and vegetable contamination and ground water pollution [14] Cadmium is a heavy metal with significant toxicity and has a destructive effect on most organs. The metal can be widely distributed in the human body, and its main sources are contamination from cigarette smoke, welding, and cadmium-contaminated foods and beverages $[15,16]$. Lead is the most importanttoxic heavy element in the environment. Due to its important physical and chemical properties, its use is very common and important. It is a very important environmental chemical that is distributed on the surface of the earth and is very dangerous. Of all the organs, the nervous system is the most affected by lead metal. However, the toxicityof this metalhas more effect on children than on adults. This is because their internal and external tis sues are softer than adults $[17,18]$. Nickel is found in very low levels in the environment. Itis present in a variety of soils and meteorites, and also erupts from the release of volcanic gases. Inhaling nickel from smoke of fossil fuels, fires and cigarettes can be very dangerous for the human respiratory and circulation system [19, 20]. Vanadium is an element found naturally in the environment and is distributed in the earth's crust at an average concentration of $100 \mathrm{mg} / \mathrm{kg}$. In general, vanadium compounds have the low toxicity. Most of the toxic effects of vanadium compounds cause local irritation of the eyes and upper respiratory tract [21]. According to the studies conducted in the field of environmental pollution and human health risk of heavy metals, it is necessary to study the spatial distribution of metals. Heavy metal spatial distribution data helps researchers identify areas where hazards are high and then present themto decision makers so that repairing methods can be implimented [22, 23]. In recent years, many studies have been conducted on heavy metal pollution, source identification, distribution pattern, pollution rate and human health risks worldwide [2, 4, 24-26]. RuizFernandez et al. [9] showed the spatial and temporal distribution of heavy metal concentrations and their enrichment in Mexican soils. Manjuladevi et al. [19] reported that the distribution of heavy metals was larger than the previously measured values in Murcia, Spain. They pointed out that heavy metal contamination in soils was mainly caused by industrial activities in the city of Murcia [19]. Zhao et al. [4] reported that potentially hazardous metals in agricultural soils are contaminated with the cadmium, copper, zinc and nickel metals in southeastern China. They also said that higher concentrations of heavy metals in the soil could adversely affect soil quality, reduce crop yields, and also contaminate crops, resulting in potential health risks to humans [4]. Jiang et al. [27] also proved that human activities have had a significant impact on the accumulation of heavy metals in urban soil in China's Jiangsu Province. Determination of heavy metal concentrations in urban soils of Rawalpindi, Pakistan showed that soil contamination by the studied cadmium, cobalt, chromium, copper, manganese, nickel, lead and zinc metals has been due to vehicle traffic and traffic and industrial effluents [28].

Therefore, due to the importance of heavy metal hazards, this study was conducted to investigate the spatial distribution of cadmium, lead, nickel and vanadium heavy metals and to determine the physical and chemical parameters of electrical conductivity, acidity and organic carbon in surface soils of Khorramabad.

\section{MATERIAL AND METHOD}

\section{Study area}

The city of Khorramabad has a position of 48 degrees and 20 minutes to 48 degrees and 23 minutes east longitude and 33 degrees and 27 minutes to 33 degrees and 33 minutes north latitude and has three urban areas and is located in Dalon north-south of the country. This has caused a large number of vehicles to pass through the crossing and communication line that passes between the city of Khorramabad, and also during the last decade, the city of Khorramabad has grown rapidly in terms of population, size and location of industries and workshops. Which all caused the spread of various types of infections.

\section{Sampling}

This descriptive cross-sectional study was conducted in 2017. In order to determine the number of sampling points according to the area of Khorramabad city, the types of land uses in the city and financial constraints; 12 sampling points were selected to conduct research (Figure 1). This choice was based on different uses

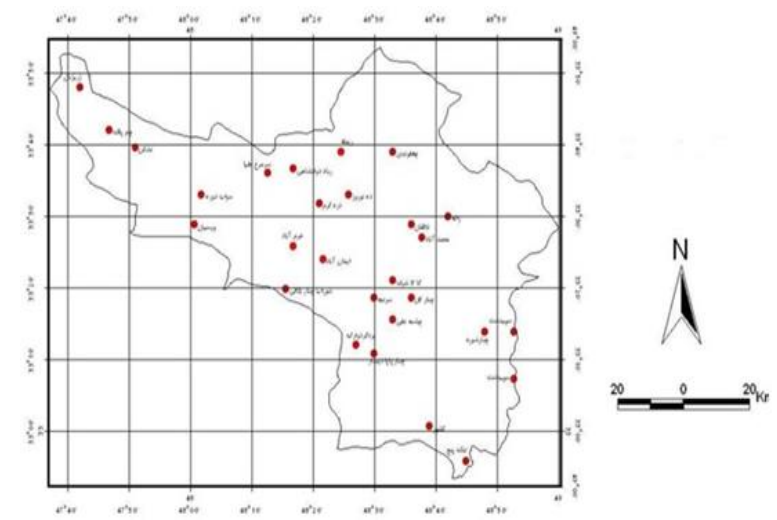

Figure 1. Geographical location of Khorramabad city and division of urban areas 
including residential, traffic and industrial. Surface soil sampling was performed in each station in 3 time periods of October, November and December 2017. Soil samples were taken from a depth of 5 to $20 \mathrm{~cm}$ mass of $1 \mathrm{~kg}$. Soil samples were then transferred to the laboratory.

\section{Measurement of parameters}

Using the standard method of the US Environmental Protection Agency, chemical digestion of soil samples and measurement of heavy metal concentrations were performed by ICP-MS method, Varian 710-ES model made in the USA. First, the soil samples were passed through a sieve with a $2 \mathrm{~mm}$ holes and worn with a porcelain mortar and turend into a soft powder for testing, then weighed $0.5 \mathrm{~g}$ for testing. For chemical digestion of soil samples, 3 to 4 drops of $1 \mathrm{~N}$ hydrochloric acid were added to it and $5 \mathrm{ml}$ of Soltani acid was added to $0.5 \mathrm{~g}$ of soil sample; and the solution was placed on the heater. Then $3 \mathrm{ml}$ of perchloric acid was added and heating was continued until the mix became almost dry. The solution was then diluted using $50 \mathrm{ml}$ of 1 Normal hydrochloric acid solution [29].

To determine the acidity of soil hub, samples were prepared according to ISO10390 standard method and then the $\mathrm{pH}$ of the sample was measured by a $\mathrm{pH}$ meter. To do this, soil samples were sieved using a sieve with a $2 \mathrm{~mm}$ Pores. Afterwards $20 \mathrm{~g}$ of each soil sample was weighed and dissolved in $50 \mathrm{ml}$ of water and mixed well, the sample was kept stationary for 17 hours and then the acidity of the smaple was measured using the device. To determine the electrical conductivity, the sample was prepared according to the ISO11265 standard method and then the electrical conductivity of the sample was measured by an EC meter. The percentage of soil's organic matter was determined by LOI (Loss On Ignition) method. Samples were prepared according to ASTM 2974-00D standards method and then the amount of organic matter was measured [30].

\section{Pollution factor}

Pollution factor (CF) was used to determine the contamination of elements in the studied top soils. In this equation, $C_{n}$ is the concentration of each element in the soil and $\mathrm{C}_{\mathrm{o}}$ is the average concentration of each element in the field. According to the classification provided by Hakanson, $\mathrm{CF}<1$ shows low pollution, $1 \leq \mathrm{CF}<3$ shows moderate pollution, $3 \leq \mathrm{CF}<6$ shows high pollution and $\mathrm{CF} \geq 6$ shows severe pollution [31]:

$$
C F={ }^{C}{ }_{C_{n}}
$$

\section{Pollution load index}

The pollution load index (PLI) was calculated using the following equation. In this formula, $\mathrm{CF}$ is the pollution factor, which is obtained from the pollution factor equation for each metal, and $\mathrm{n}$ is the number of metals studied. Pollution load index values vary from zero (noncontaminated) to 10 (highly contaminated). Typically, values less than 1 indicate no contamination, and values greater than 1 indicate contamination with heavy metals [31]:

$$
P L I=\sum \text { CF Metals } / n
$$

\section{Nemro pollution index}

Nemro pollution index (NPI) was calculated using Equation (3). Based on this index, soil quality is classified into five soil levels: without pollution $\mathrm{NPI}<0.7$, pollution warning line $0.7 \leq \mathrm{NPI}<1$, low pollution level $1 \leq \mathrm{NPI}<2$, medium pollution level $2 \leq \mathrm{NPI}<3$ and high pollution level NPI $\geq 3[32]$ :

$$
N P I=\sqrt{\frac{P I_{\text {imax }}^{2}+P I_{\text {iave }}^{2}}{2}}
$$

\section{Enrichment factor}

The enrichment factor (EF) for each metal was calculated from the ratio between the normalizing element to the background value of the elements, according to the following equation. The reference element in determining the enrichment factor is an element that has a purely geological origin. In this research, the iron element was used as a reference metal. According to the proposed classification, $\mathrm{EF}<2$ shows low pollution, $2 \leq \mathrm{EF}<5$ shows moderate pollution, $5 \leq \mathrm{EF}<20$ shows high pollution, $20 \leq \mathrm{EF}<40$ shows very high pollution, and $\mathrm{EF} \geq 40$ shows extremely high pollution [31]:

$$
E F=\frac{(\text { Metal } / F e)_{\text {Sample }}}{(\text { Metal } / F e)_{\text {Background }}}
$$

\section{Ecological risk}

Ecological risk (Er) assessment was calculated from Equation (5). In this regard, CF stands for pollution factor, and Er shows the ecological risk of each element under study. Hakans on [31] defined the TR value, which is an indicator of the toxicity of heavy metals, for the analysis of the obtained values into four different groups. Ecological risk for each element is classified into five levels: low risk $\mathrm{Er}<40$, medium risk $40 \leq \mathrm{Er}<80$, significant risk $80 \leq \mathrm{Er}<160$, high risk $160 \leq \mathrm{Er}<320$ and very high risk $\mathrm{Er} \geq 320$ [31]:

$$
E r=T R \times C F
$$

\section{Accumulation index}

Accumulation index $\left(\mathrm{I}_{\mathrm{geo}}\right)$ can determine the degree of soil pollution. This index, first proposed by Muller, is used in environmental analysis to identify contaminated surfaces and was calculated from Equation (6). In this regard, Igeo is the land accumulation index, $C_{n}$ is the concentration of heavy metal in the soil, $\mathrm{B}_{\mathrm{n}}$ is the concentration of the ground (average shale). In this 
regard, in order to modify the effects of soil parent materials and natural fluctuations in the given substance's content in the environment, a coefficient of 1.5 was used. It also corrects very little change caused by human activities. Muller Classification Basis classifies into seven classes of contamination: Igeo $<0$ non-contaminated, $0 \leq \mathrm{I}_{\text {geo }}<1$ non-contaminated to slightly contaminated, $1 \leq \mathrm{I}_{\text {geo }}<2$ slightly contaminated, $2 \leq \mathrm{I}_{\text {geo }}<3$ slightly contaminated to highly contaminated, $3 \leq \mathrm{I}_{\text {geo }}<4$ highly contaminated, $4 \leq \mathrm{I}_{\text {geo }}<5$ highly contaminated Severely infected and highly $I_{g e o} \geq 5$ highly classified [33]:

$$
I_{\text {geo }}=\log _{2}\left(C_{n} / 1.5 B_{n}\right)
$$

\section{Statistical analysis}

In order to statistically process the data, SPSS V.18 software was used. The normality of the data was checked by the Kolmograph-Smirnov test. To confirm the type of data distribution, the Kolmogorov-Smirnov test was used at $95 \%$ confidence level. One-way analys is of variance (ANOVA) was used to compare the mean concentrations of the evaluated elements between sampling stations. The relationship between variables was examined using the Pearson correlation test. The Microsoft Excel software was used to draw tables and graphs.

\section{RESULTS AND DISCUSSION}

The results of measuring the physicochemical parameters of the soil of the region, which include the parameters of acidity, organic matter, and soil texture, are summarized in Table 1. The highest amount of $\mathrm{pH}$ in the $4^{\text {th }}$ station is 7.7 and the lowest amount is in the $6^{\text {th }}$ stationis 6.9. The highest electrical conductivity was measured in the $12^{\text {th }}$ stationat the rate of 4.8 microsiemens per centimeter and the lowest in the $7^{\text {th }}$ stationat 0.74 . The highest amount of organic matter observed in the $5^{\text {th }}$ station was $3.21 \%$ and the lowest amount was recorded in the first station at $0.06 \%$.

Descriptive statistics for heavy metals including mean, standard deviation, standard error, variance, skewness, and elongation coefficients are presented in Table 2. Apart from the mean, other statistics are part of the dispersion indices and are used to determine the type of test used (parametric or non-parametric). Results are also provided for verification and validation. The standard deviation in the nickel parameter is 46.41 , which shows a relatively large dispersion. However, this value for the cadmium parameter is 4.58 .

Temporal and spatial variations of the measured elements in the 12 sampling areas are presented in Figures

Table 1. Levels of some soil phy sical and chemical parameters of the surface of Khorramabad

\begin{tabular}{|c|c|c|c|c|c|}
\hline Area & Stations & pH & $\mathrm{Ec}(\mathrm{ms} / \mathrm{cm})$ & $\operatorname{soc}(\%)$ & Soil texture \\
\hline \multirow{3}{*}{ Industrial } & 1 & 7.1 & 4.13 & 0.06 & Loamy - clay \\
\hline & 2 & 7.4 & 1.37 & 1.95 & Loamy - clay \\
\hline & 3 & 7.2 & 3.32 & 1.53 & Sandy - clay \\
\hline \multirow{5}{*}{ Traffic } & 4 & 7.7 & 2.6 & 2.4 & Sandy - clay \\
\hline & 5 & 7.3 & 1.13 & 3.21 & Sandy - clay \\
\hline & 6 & 9.6 & 2.93 & 2.22 & clay \\
\hline & 7 & 7.8 & 0.74 & 2.58 & Sandy clay loam \\
\hline & 8 & 7.5 & 1.2 & 0.9 & Sandy - clay \\
\hline \multirow{4}{*}{ Residential } & 9 & 7.3 & 2.65 & 0.96 & Clay loam \\
\hline & 10 & 7.5 & 1.79 & 3 & clay \\
\hline & 11 & 7.6 & 1.45 & 2.16 & Loamy - clay \\
\hline & 12 & 8 & 4.8 & 3.03 & Loamy - clay \\
\hline
\end{tabular}

Table 2. Descriptive statistics were aggregated to measure heavy metals

\begin{tabular}{lcccccc}
\hline Metals & Mean & Standard error & Standard deviation & Variance & Skewness & Kurtosis \\
\hline $\mathrm{Pb}$ & 14.2500 & 0.56817 & 3.40902 & 11.621 & 0.172 & -0.613 \\
$\mathrm{Ni}$ & 45.6667 & 1.64558 & 9.87349 & 97.486 & -0.647 & -0.813 \\
$\mathrm{Cd}$ & 4.6389 & 0.22591 & 1.35547 & 1.837 & -0.384 & -0.297 \\
$\mathrm{~V}$ & 32.6111 & 1.64137 & 9.84821 & 96.987 & 0.327 & -1.087 \\
\hline
\end{tabular}


2, 3, 4 and 5. The highest amount of cadmium was observed in the soil samples of Industrial Town No. 1 in the two sampling periods of October and December at 7 $\mathrm{ppm}$. The lowest amount was measured in the $8^{\text {th }}$ station and $11^{\text {th }}$ station to be $2 \mathrm{ppm}$. The measurement showed that the maximum amount of lead is equal to $22 \mathrm{ppm}$ at the sixth station, which is a busy area. The average nickel in industrial areas was higher than in other areas. In industrial town No. 1, during the sampling period of October, its amount was measured to be $58 \mathrm{mg} / \mathrm{kg}$. The highest amount of vanadium was recorded in $9^{\text {th }}$ station to be $52 \mathrm{mg} / \mathrm{kg}$.

A comparis on of the mean measured values of heavy elements in residential, traffic, and industrial sampling areas is shown in Figure 6. These results showed that the highest average amount of heavy elements are in industrial areas and the lowest in residential areas.

The results of Pearson correlation test between the studied variables are shown in Table 3. Lead has a significant correlation with nickel, cadmium and soil acidity. This correlation is $0.01 \%$ for acidity and cadmium variables and $0.03 \%$ for nickel. Nickel has a

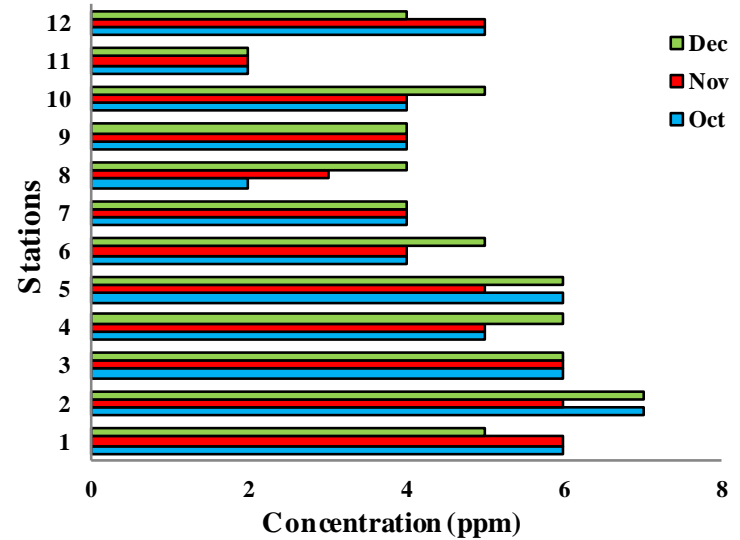

Figure 2. Spatial variations of cadmium levels in surface soils of Khorramabad

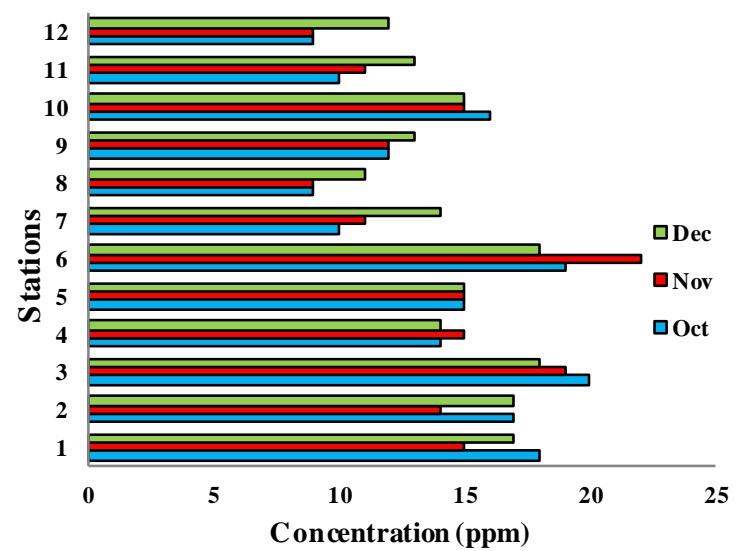

Figure 3. Spatial variations of lead levels in surface soils of Khorramabad

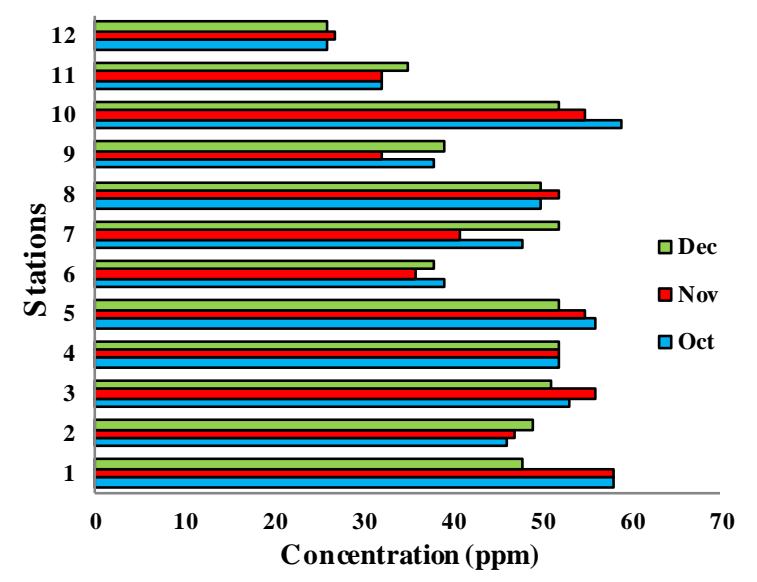

Figure 4. Spatial variations of nickle levels in surface soils of Khorramabad

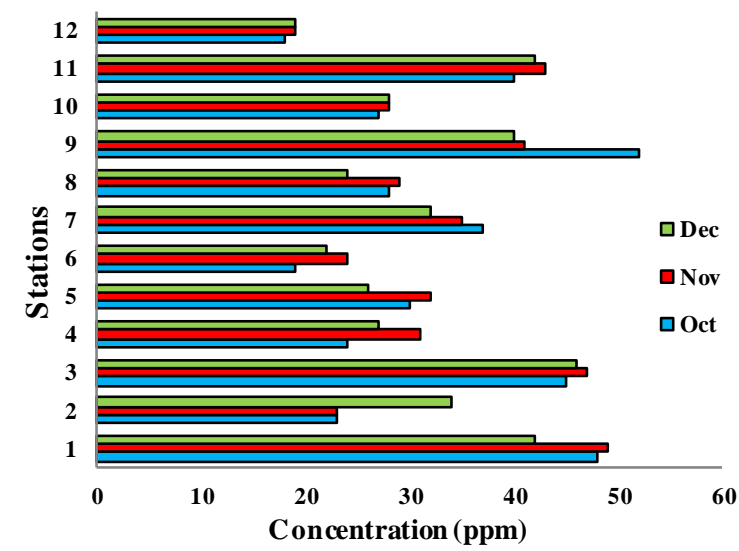

Figure 5. Spatial variations of vanadium levels in surface soils of Khorramabad

significant correlation with cadmium and vanadium at the level of 0.01 . The element vanadium has a significant correlation with the values of electrical conductivity and nickel. The cluster analysis dendrogram of the research variables is presented in Figure 7. Based on cluster analysis, metals and parameters were divided into two main groups; The first group includes cadmium, lead, acidity, electrical conductivity, and soil organic carbon and the second group includes vanadium and nickel.

According to the results of the pollution factor, heavy metals cadmium, lead, nickel, and vanadium in the surface soils of Khorramabad had low pollution, with the highest amount of pollution factor being related to cadmium metal at the first station (1.4) and the lowest level of this index being related to Vanadium metal was obtained in $12^{\text {th }}$ station (0.11) (Table 4$)$.

The results of land accumulation index showed that the heavy metals cadmium, lead, nickel, and vanadium in the surface soils of Khorramabad were free of contamination, cadmium metal was moderately contaminated only in the first and second stations. Also, 


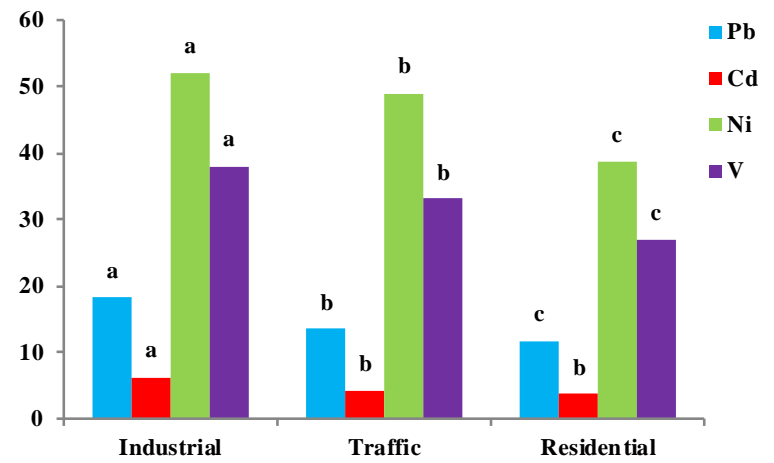

Figure 6. Comparison of the average of heavy metals in surface soils of Khorramabad; Different letters in each column showed a significant difference for each metal $(\mathrm{P}<0.05)$.

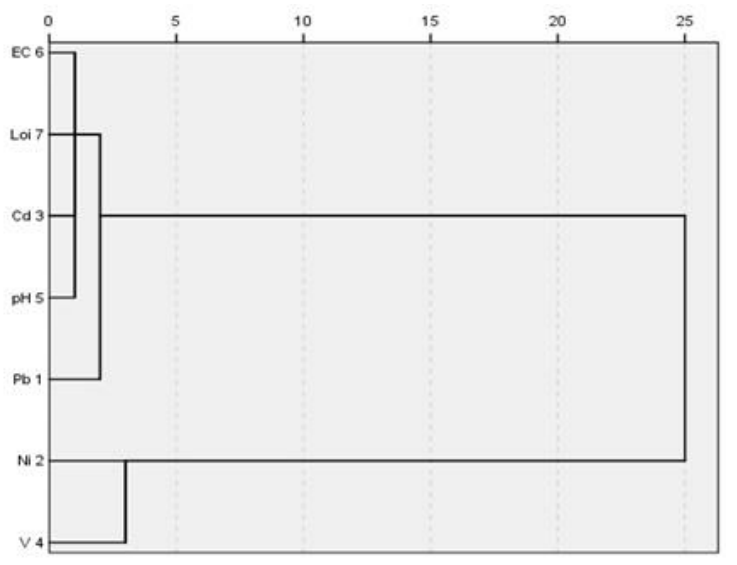

Figure 7. Dendrogram cluster analy sis of research variables

Table 3. Effluent quality and removal percentage of the jar test experiment

\begin{tabular}{|c|c|c|c|c|c|c|c|}
\hline Parameters & & $\mathbf{P b}$ & $\mathbf{N i}$ & Cd & $\mathbf{V}$ & pH & EC \\
\hline \multirow{2}{*}{$\mathrm{Pb}$} & Pearson & 1 & $0.386^{*}$ & $0.539^{* *}$ & 0.126 & $-0.734^{* * *}$ & 0.200 \\
\hline & Sig. (2-tailed) & $*$ & 0.020 & 0.001 & 0.466 & 0.000 & 0.242 \\
\hline \multirow{2}{*}{$\mathrm{Ni}$} & Pearson & $*$ & 1 & $0.428^{* *}$ & 0.710 & -0.301 & -0.306 \\
\hline & Sig. (2-tailed) & $*$ & * & 0.009 & 0.019 & 0.074 & 0.070 \\
\hline \multirow{2}{*}{$\mathrm{Cd}$} & Pearson & $*$ & $*$ & 1 & -0.034 & -0.257 & 0.266 \\
\hline & Sig. (2-tailed) & $*$ & * & * & 0.842 & 0.130 & 0.117 \\
\hline \multirow{2}{*}{$\mathrm{V}$} & Pearson & $*$ & $*$ & * & 1 & -0.306 & 0.047 \\
\hline & Sig. (2-tailed) & $*$ & * & $*$ & $*$ & 0.070 & 0.787 \\
\hline \multirow{2}{*}{$\mathrm{pH}$} & Pearson & $*$ & $*$ & $*$ & $*$ & 1 & -0.085 \\
\hline & Sig. (2-tailed) & $*$ & $*$ & $*$ & $*$ & $*$ & 0.620 \\
\hline \multirow{2}{*}{$\mathrm{EC}$} & Pearson & $*$ & $*$ & $*$ & $*$ & $*$ & 1 \\
\hline & Sig. (2-tailed) & $*$ & * & * & $*$ & $*$ & $*$ \\
\hline
\end{tabular}

* The relationship is significant at the 0.05 level.

** The relationship is significant at the 0.01 level.

the highest values of land accumulation index of cadmium metal were 2.27 and 1.31. However the lowest value of this metal was 0.075 in $12^{\text {th }}$ station (Table 5).

According to the results of the pollution index, heavy metals cadmium, lead, nickel and vanadium in the surface soils of Khorramabad had low pollution, with the highest amount of nickel-metal pollution factor was measured 10th station (0.369) and the lowest level of this index was related to Vanadium and was obtained at $12^{\text {th }}$ station (0.0563) (Table 6).

The results of Nemro contamination index also showed the absence of heavy metal contamination in the surface soils of Khorramabad, only cadmium metal in first station (1.34) had moderate contamination. The highest score index values for lead, nickel and vanadium were obtained in second $10^{\text {th }}$, and $9^{\text {th }}$ stations to be 0.37 , 0.63 , and 0.276 , respectively. Also, the lowest values of the Nemro pollution index for nickel and vanadium in $12^{\text {th }}$ and $6^{\text {th }}$ stations were 0.28 and 0.101 , respectively (Table 7).

The results of the enrichment factor showed that the heavy metals cadmium, lead, nickel and vanadium in the surface soils of Khorramabad in all stations studied are of natural origin and anthropogenic activities had a small role in the pollution of these metals. The highest values of enrichment factor related to nickel metal in tenth station were 0.738 , but the lowest value of this index was related to vanadium metal and was measured to be 0.1125 in $12^{\text {th }}$ station (Table 8).

Ecological risk as sessment of heavy metals cadmium, lead, nickel and vanadium in the surface soils of Khorramabad in all studied stations showed that they were at low risk. The highest ecological risk values of cadmium, lead, nickel, and vanadium were obtained in second, third, $10^{\text {th }}$, and $9^{\text {th }}$ stationsto be $24.733,21.78$, 20.65 and 11.05 respectively (Table 9). 
Table 4. Results of heavy metal contamination factor in surface soils of Khorramabad

\begin{tabular}{lcccccccc}
\hline \multirow{2}{*}{ Stations } & \multicolumn{2}{c}{ Cd } & \multicolumn{2}{c}{ Pb } & \multicolumn{2}{c}{ Ni } & \multicolumn{2}{c}{ V } \\
\cline { 2 - 9 } & Values & Pollution & Values & Pollution & Values & Pollution & Values & Pollution \\
\hline 1 & 1.4 & Low & 0.4 & Low & 0.73 & Low & 0.3 & Low \\
2 & 0.467 & Low & 0.38 & Low & 0.58 & Low & 0.14 & Low \\
3 & 0.4 & Low & 0.44 & Low & 0.66 & Low & 0.28 & Low \\
4 & 0.333 & Low & 0.31 & Low & 0.65 & Low & 0.15 & Low \\
5 & 0.4 & Low & 0.33 & Low & 0.7 & Low & 0.19 & Low \\
6 & 0.267 & Low & 0.42 & Low & 0.49 & Low & 0.12 & Low \\
7 & 0.267 & Low & 0.22 & Low & 0.6 & Low & 0.23 & Low \\
8 & 0.133 & Low & 0.2 & Low & 0.63 & Low & 0.18 & Low \\
9 & 0.267 & Low & 0.27 & Low & 0.48 & Low & 0.33 & Low \\
10 & 0.267 & Low & 0.36 & Low & 0.74 & Low & 0.17 & Low \\
11 & 0.133 & Low & 0.22 & Low & 0.4 & Low & 0.25 & Low \\
12 & 0.333 & Low & 0.2 & Low & 0.33 & Low & 0.11 & Low \\
\hline
\end{tabular}

Table 5. Results of heavy metal $\mathrm{I}_{\mathrm{geo}}$ index in surface soils of Khorramabad

\begin{tabular}{lcccccccc}
\hline \multirow{2}{*}{ Stations } & \multicolumn{2}{c}{ Cd } & \multicolumn{2}{c}{ Pb } & \multicolumn{2}{c}{ Ni } & \multicolumn{1}{l}{ V } \\
\cline { 2 - 8 } & Values & Pollution & Values & Pollution & Values & Pollution & Values & Pollution \\
\hline 1 & 2.27 & Medium & 0.27 & No pollution & 0.48 & No pollution & 0.2 & No pollution \\
2 & 1.31 & Medium & 0.25 & No pollution & 0.38 & No pollution & 0.096 & No pollution \\
3 & 0.67 & No pollution & 0.3 & No pollution & 0.44 & No pollution & 0.188 & No pollution \\
4 & 0.22 & No pollution & 0.21 & No pollution & 0.43 & No pollution & 0.1 & No pollution \\
5 & 0.27 & No pollution & 0.22 & No pollution & 0.47 & No pollution & 0.125 & No pollution \\
6 & 0.18 & No pollution & 0.28 & No pollution & 0.33 & No pollution & 0.079 & No pollution \\
7 & 0.18 & No pollution & 0.15 & No pollution & 0.4 & No pollution & 0.154 & No pollution \\
8 & 0.09 & No pollution & 0.13 & No pollution & 0.42 & No pollution & 0.117 & No pollution \\
9 & 0.18 & No pollution & 0.18 & No pollution & 0.32 & No pollution & 0.217 & No pollution \\
10 & 0.18 & No pollution & 0.24 & No pollution & 0.49 & No pollution & 0.113 & No pollution \\
11 & 0.09 & No pollution & 0.15 & No pollution & 0.27 & No pollution & 0.167 & No pollution \\
12 & 0.22 & No pollution & 0.13 & No pollution & 0.22 & No pollution & 0.075 & No pollution \\
\hline
\end{tabular}

Table 6. Results of heavy metal PLI in surface soils of Khorramabad

\begin{tabular}{lcccccccc}
\hline \multirow{2}{*}{ Stations } & \multicolumn{2}{c}{ Cd } & \multicolumn{2}{c}{ Pb } & \multicolumn{2}{c}{ Ni } & \multicolumn{2}{c}{ V } \\
\cline { 2 - 9 } & Values & Pollution & Values & Pollution & Values & Pollution & Values & Pollution \\
\hline 1 & 0.2 & Low & 0.2 & Low & 0.363 & Low & 0.15 & Low \\
2 & 0.23 & Low & 0.19 & Low & 0.288 & Low & 0.0719 & Low \\
3 & 0.2 & Low & 0.22 & Low & 0.331 & Low & 0.1406 & Low \\
4 & 0.17 & Low & 0.16 & Low & 0.325 & Low & 0.075 & Low \\
5 & 0.2 & Low & 0.17 & Low & 0.35 & Low & 0.0938 & Low \\
6 & 0.13 & Low & 0.21 & Low & 0.244 & Low & 0.0594 & Low \\
7 & 0.13 & Low & 0.11 & Low & 0.3 & Low & 0.1156 & Low \\
8 & 0.07 & Low & 0.1 & Low & 0.313 & Low & 0.0875 & Low \\
9 & 0.13 & Low & 0.13 & Low & 0.238 & Low & 0.1625 & Low \\
10 & 0.13 & Low & 0.18 & Low & 0.369 & Low & 0.0844 & Low \\
11 & 0.07 & Low & 0.11 & Low & 0.2 & Low & 0.125 & Low \\
12 & 0.17 & Low & 0.1 & Low & 0.163 & Low & 0.0563 & Low \\
\hline
\end{tabular}


Table 7. Results of heavy metal Nemro pollution index in surface soils of Khorramabad

\begin{tabular}{|c|c|c|c|c|c|c|c|c|}
\hline \multirow{2}{*}{ Stations } & \multicolumn{2}{|c|}{$\mathrm{Cd}$} & \multicolumn{2}{|c|}{$\mathbf{P b}$} & \multicolumn{2}{|c|}{$\mathrm{Ni}$} & \multicolumn{2}{|c|}{$\mathbf{V}$} \\
\hline & Values & Pollution & Values & Pollution & Values & Pollution & Values & Pollution \\
\hline 1 & 1.34 & Medium & 0.32 & No pollution & 0.62 & No pollution & 0.255 & No pollution \\
\hline 2 & 0.397 & No pollution & 0.37 & No pollution & 0.49 & No pollution & 0.122 & No pollution \\
\hline 3 & 0.34 & No pollution & 0.32 & No pollution & 0.56 & No pollution & 0.239 & No pollution \\
\hline 4 & 0.283 & No pollution & 0.27 & No pollution & 0.55 & No pollution & 0.128 & No pollution \\
\hline 5 & 0.34 & No pollution & 0.32 & No pollution & 0.6 & No pollution & 0.159 & No pollution \\
\hline 6 & 0.227 & No pollution & 0.21 & No pollution & 0.41 & No pollution & 0.101 & No pollution \\
\hline 7 & 0.227 & No pollution & 0.21 & No pollution & 0.51 & No pollution & 0.197 & No pollution \\
\hline 8 & 0.113 & No pollution & 0.11 & No pollution & 0.53 & No pollution & 0.149 & No pollution \\
\hline 9 & 0.227 & No pollution & 0.21 & No pollution & 0.4 & No pollution & 0.276 & No pollution \\
\hline 10 & 0.227 & No pollution & 0.21 & No pollution & 0.63 & No pollution & 0.143 & No pollution \\
\hline 11 & 0.113 & No pollution & 0.11 & No pollution & 0.34 & No pollution & 0.213 & No pollution \\
\hline 12 & 0.283 & No pollution & 0.27 & No pollution & 0.28 & No pollution & 0.096 & No pollution \\
\hline
\end{tabular}

Table 8. Results of heavy metal enrichment factorin surface soils of Khorramabad

\begin{tabular}{|c|c|c|c|c|c|c|c|c|}
\hline \multirow{2}{*}{ Stations } & \multicolumn{2}{|c|}{ Cd } & \multicolumn{2}{|c|}{$\mathbf{P b}$} & \multicolumn{2}{|c|}{$\mathbf{N i}$} & \multicolumn{2}{|c|}{$\mathbf{V}$} \\
\hline & Values & Pollution & Values & Pollution & Values & Pollution & Values & Pollution \\
\hline 1 & 0.4 & Natural & 0.4 & Natural & 0.725 & Natural & 0.3 & Natural \\
\hline 2 & 0.467 & Natural & 0.378 & Natural & 0.575 & Natural & 0.1438 & Natural \\
\hline 3 & 0.4 & Natural & 0.444 & Natural & 0.663 & Natural & 0.2813 & Natural \\
\hline 4 & 0.333 & Natural & 0.311 & Natural & 0.65 & Natural & 0.15 & Natural \\
\hline 5 & 0.4 & Natural & 0.333 & Natural & 0.7 & Natural & 0.1875 & Natural \\
\hline 6 & 0.267 & Natural & 0.422 & Natural & 0.488 & Natural & 0.1188 & Natural \\
\hline 7 & 0.267 & Natural & 0.222 & Natural & 0.6 & Natural & 0.2313 & Natural \\
\hline 8 & 0.133 & Natural & 0.2 & Natural & 0.625 & Natural & 0.175 & Natural \\
\hline 9 & 0.267 & Natural & 0.267 & Natural & 0.475 & Natural & 0.325 & Natural \\
\hline 10 & 0.267 & Natural & 0.356 & Natural & 0.738 & Natural & 0.1688 & Natural \\
\hline 11 & 0.133 & Natural & 0.222 & Natural & 0.4 & Natural & 0.25 & Natural \\
\hline 12 & 0.333 & Natural & 0.2 & Natural & 0.325 & Natural & 0.1125 & Natural \\
\hline
\end{tabular}

Table 9. Results of heavy metal ecological risk in surface soils of Khorramabad

\begin{tabular}{|c|c|c|c|c|c|c|c|c|}
\hline \multirow{2}{*}{ Stations } & \multicolumn{2}{|c|}{ Cd } & \multicolumn{2}{|c|}{$\mathbf{P b}$} & \multicolumn{2}{|c|}{$\mathrm{Ni}$} & \multicolumn{2}{|c|}{$\mathbf{V}$} \\
\hline & Values & Pollution & Values & Pollution & Values & Pollution & Values & Pollution \\
\hline 1 & 21.2 & Low & 19.6 & Low & 20.3 & Low & 10.2 & Low \\
\hline 2 & 24.733 & Low & 18.51 & Low & 16.1 & Low & 4.888 & Low \\
\hline 3 & 21.2 & Low & 21.78 & Low & 18.55 & Low & 9.563 & Low \\
\hline 4 & 17.667 & Low & 15.24 & Low & 18.2 & Low & 5.1 & Low \\
\hline 5 & 21.2 & Low & 16.33 & Low & 19.6 & Low & 6.375 & Low \\
\hline 6 & 14.133 & Low & 20.69 & Low & 13.65 & Low & 4.038 & Low \\
\hline 7 & 14.133 & Low & 10.89 & Low & 16.8 & Low & 7.863 & Low \\
\hline 8 & 7.0667 & Low & 9.8 & Low & 17.5 & Low & 5.95 & Low \\
\hline 9 & 14.133 & Low & 13.07 & Low & 13.3 & Low & 11.05 & Low \\
\hline 10 & 14.133 & Low & 17.42 & Low & 20.65 & Low & 5.738 & Low \\
\hline 11 & 7.0667 & Low & 10.89 & Low & 11.2 & Low & 8.5 & Low \\
\hline 12 & 17.667 & Low & 9.8 & Low & 9.1 & Low & 3.825 & Low \\
\hline
\end{tabular}


In this study, the average amount of cadmium and nickel metals in the surface soils of Khorramabad was higher than the concentration of these elements in the earth's crust, but the amount of lead and vanadium was lower. The mean background concentrations of cadmium, lead, nickel and vanadium are $0.25,57.57,40.74$ and 110 $\mathrm{mg} / \mathrm{kg}$, respectively [29, 34]. According to the obtained results, it can be stated that higher levels of cadmium and nickel metals than the concentration of the field indicate that anthropogenic activities have increased the amount of metals' concentration in the soil of the study area.

The variable of sampling area had a significant effect on the concentration of heavy elements $(\mathrm{P}<0.05)$. For nickel and cadmium, the P-value is less than 0.01 , so spatial variations have a great impact on the concentration of these two elements. The value of $P$ in the lead element is calculated to be 0.032 , which indicates the existence of a significant difference between the stations at the level of 0.05. Although spatialchanges in this element had less effect than other elements. However, these changes are statistically significant $(\mathrm{P}<0.05)$. The value of $\mathrm{P}$ was calculated to be 0.02 for the element vanadium, which shows that the concentration of this element in the measuring stations was significantly different at the level of $0.003(\mathrm{P}<0.05)$. Leads are derived from fossil fuels and their main source in urban environments is vehicle traffic $[17,18]$, Therefore, a significant difference in lead concentrations in traffic stations with other areas can be explained. Many studies attribute high levels of lead in soil to industrial and anthropogenic activities [7, 9-11].

Sampling areas (residential, industrial and traffic) were not effective in the concentrations of the studied elements for lead, nickel and vanadium $(\mathrm{P}>0.05)$. But, for the element nickel, these values had a significant difference at the level of $0.05(\mathrm{P}<0.05)$. However, the average concentration of all elements in industrial areas was more than traffic and residential areas. Statistical analysis shows that there was a significant difference between traffic and industrial areas as well as industrial $(\mathrm{P}<0.05)$. The average concentration of vanadium and nickel in industrial areas was higher than residential areas. Therefore, it can be inferred that because nickel is released from fossil fuels into the environment [20, 26], through the ceramics industry, the production of special batteries, electronics industry, manufacturing of steel tools and equipment enters the environment [35], and the release of vanadium into the environment is mainly associated with industrial resources, especially oil refineries and coal power plants [21, 36], for these reasons, the amount of nickel and vanadium in the soil of industrial areas were higher than residential areas.

Cadmium levels in traffic and industrial areas are higher than in residential areas, which is obvious; but, it should be noted that the amount of cadmium in residential areas is also higher than the concentration of this element in the earth's crust. It should also be noted that soil cadmium levels are strongly influenced by human agricultural and industrial activities [16, 27]. The metal enters the environment through activities such as mining, metal industry, chemical industry, metal working water, superphosphate fertilizers, cadmium-containing pesticides, as well as the production of some metal alloys and battery manufacturing [35].

Correlation analyzes show a correlation between lead and nickel, cadmium and acidity. This correlation is 0.01 for acidity and cadmium variables and 0.03 for nickel and lead. Nickel has a significant correlation with cadmium and vanadium at the level of 0.01 . The element vanadium has a significant correlation with the values of electrical conductivity and nickel. Based on cluster analys is, metals and parameters were divided into two main groups; The first group included cadmium, lead, acidity, electrical conductivity, and soil organic carbon and the second group included vanadium and nickel. Different cluster groups represent differences in the geochemical behavior and different origins of metals. Therefore, the metals in a group have the same and natural origin. Cluster analys is is a multivariate statistical method used in this study to identify the origin of elements. The cluster tree connects homogenous options to create larger clusters and to measure similarities between specimens [37, 38].

The mean concentrations of heavy metals lead and cadmium in the surface soils of Bojnourd were 9.10, 63, 3.63 and $0.20,18,0.18 \mathrm{mg} / \mathrm{kg}$, respectively. The concentration of heavy metals in the urban soil of Bojnourd may be due to traffic and industrial activities [39]. Heavy metal contamination has also been reported in surface soils around AhvazIndustrial Town No. 2 [40]. In all areas of Zahedan (except residential areas), the average concentration of cadmium, chromium, copper, nickel, lead, and zinc was higher than the concentration of the background. Concentrations of cadmium, chromium, copper, nickel, lead and zinc were $0.1,37.53$ 96 6.96, $29.541010 .25,51.988 .53,25.25$, respectively. It was $28.376,184.309425 .94 \mathrm{mg} / \mathrm{kg}$ of soil. The results of this study showed that land use has a significant effect on increasing the concentration of heavy metals in the surface soil of Zahedan. The highest concentrations of metals were obtained in commercial and high-traffic areas where there was higher vehicle traffic in the mentioned areas, so reducing traffic and improving the public transportation system in these areas can lead to improved soil quality in these areas [25]. In another study, the concentration of lead and cadmium in soils of different regions of Is fahan has been reported to be higher than the global average [41]. The average concentrations of heavy metals vanadium and nickel in roadside soils around the Rasht-Qazvin freeway were 46.63 and 9.48 $\mathrm{mg} / \mathrm{kg}$. Based on the results obtained in this study, the surface soils of the study area are slightly polluted in terms of the studied metals, but studies of environmental conditions showed that des pite the results, concerns about 
the release of pollution load in the soils around the freeway should always be present; because due to the existence of agricultural fields in the region, a significant part of the metals are removed from the environment by crops every year during the process of biosorption [42]. According to the results of the mentioned studies, various industries such as metal mining to computers and electronics, chemical fertilizer factories, dyeing, textile, weapons and thermal power plants, oil and petrochemical industries, steel and piping industries, hospitals and slaughterhouses livestock, and poultry are involved in causing heavy metal pollution [43, 44]. Metallic elements such as copper, nickel, lead and cadmium are in the group of human activities and enter the soil through the use of chemical fertilizers, fungicides, industry, and sewage sludge [45]. In other words, human activities, especially agricultural effluents, industrial wastewaters, and pollution from the transportation industry cause a significant amount of heavy metals to enter the environment [46].

Assessment of soil heavy metals for the environment and human health in Yangtze Basin region of China shows a moderate enrichment factor for cadmium and selenium was observed. The potential ecological risk index shows a significant difference in the areas with moderate risk. However, several relatively severe areas were contaminated with cadmium, arsenic, and mercury by the land accumulation index, and as a result, these areas were classified as a significant risk or high risk [47] Adedeji et al. [48] investigated the spatial distribution and health risk assessment of soil contamination by the heavy metals cadmium, chromium, copper, manganese, nickel, lead, and zinc in Ijebu-Ode, Nigeria. Geographic Information System (GIS) data, pollution indices (enrichment factor, Igeo index) and health risk assessment model were used to analyze the spatial distribution, pollution level and potential health risk of heavy metals, respectively. The average concentrations of the seven heavy metals studied are as followss: zinc> lead $>$ manganese > copper> cadmium> nickel> chromium, respectively. There is a great deal of spatial variation in the distribution patterns of heavy metals. Cancer risks of copper, manganese, lead and zinc for children and manganese, lead and zinc for adults were higher than acceptable. Anthropological activities resulting from various urban uses are involved in the level of pollution and spatial distribution of heavy metals in the soil. Increased urban soil pollution may contribute to some health risks for residents of the study area [48]. According to the results presented in this study and other studies and research, biological monitoring of heavy metals in soil and plants should be carried out continuously and intermittently, because studies and research on heavy metals show that if, in the coming years, safety rules are not implemented environmentally the concentration of heavy metals in the soil will increase and as a result, they will be transferred to plants and enter the human food cycle, and diseases caused by heavy metals will be more prevalent $[49,50]$.

\section{CONCLUSIONS}

The results of the calculations of the studied pollution indices showed that the intensity of pollution in first and second stations (industrial towns) is high. In third station is at the the middle level and other stations are free of pollution. In fact, first and second stations are moderately polluted and other stations are free of pollution. The results of the ecological risk assessment also showed that only in the industrial town's stations the ecological risk is at a moderate level for the cadmium element. At other stations, the ecological risk is low. The results showed that the natural share of each of the studied heavy metals is more than the share of man-made effects in a way that the man-made effects reache zero, the highest share of man-made effectsare cadmium and then lead. For the elements of nickel and vanadium, the man-made component is negligible. The results indicate that the surface soil of Khorramabad is not contaminated with the studied metals. In general, the results showed that human and natural factors are always involved in the distribution and concentration of heavy metals.

\section{REFERENCES}

1. Jie, C., Jing-zhang, C., Man-zhi, T., and Zi-tong, G. 2002. "Soil degradation: a global problem endangering sustainable development." Journal of Geographical Sciences, 12(2), pp.243252. https://doi.org/10.1007/BF02837480

2. Ahmadi, M., Akhbarizadeh, R., Haghighifard, N. J., Barzegar, G., and Jorfi, S. 2019. "Geochemical determination and pollution assessment of heavy metals in agricultural soils of south western of Iran." Journal of Environmental Health Science and Engineering, 17(2), pp.657-669. https://doi.org/10.1007/s40201-019-00379-6

3. Qingjie, G., Jun, D., Yunchuan, X., Qingfei, W., and Liqiang, Y. 2008. "Calculating Pollution Indices by Heavy Metals in Ecological Geochemistry Assessment and a Case Study in Parks of Beijing." Journal of China University of Geosciences, 19(3), pp.230-241. https://doi.org/10.1016/S1002-0705(08)60042-4

4. Zhao, K., Fu, W., Qiu, Q., Ye, Z., Li, Y., Tunney, H., Dou, C., Zhou, K., and Qian, X. 2019. "Spatial patterns of potentially hazardous metals in paddy soils in a typical electrical waste dismantling area and their pollution characteristics." Geoderma, 337, pp.453-462. https://doi.org/10.1016/j.geoderma.2018.10.004

5. Suvarapu, L. N., and Baek, S.-O. 2017. "Determination of heavy metals in the ambient atmosphere." Toxicology and Industrial $\begin{array}{lll}\text { Health, 33(1), } & \text { pp.79-96. }\end{array}$ https://doi.org/10.1177/0748233716654827

6. Ying, L., Shaogang, L., and Xiaoyang, C. 2016. "Assessment of heavy metal pollution and human health risk in urban soils of a coal mining city in East China." Human and Ecological Risk Assessment: An International Journal, 22(6), pp.1359-1374. https://doi.org/10.1080/10807039.2016.1174924

7. Doabi, S. A., Karami, M., Afyuni, M., and Yeganeh, M. 2018. "Pollution and health risk assessment of heavy metals in agricultural soil, atmospheric dust and major food crops in 
Kermanshah province, Iran." Ecotoxicology and Environmental Safety, 163 , https://doi.org/10.1016/j.ecoenv.2018.07.057

pp.153-164.

8. Wu, J., Lu, J., Li, L., Min, X., and Luo, Y. 2018. "Pollution, ecological-health risks, and sources of heavy metals in soil of the northeastern Qinghai-Tibet Plateau." Chemosphere, 201, pp.234 242. https://doi.org/10.1016/j.chemosphere.2018.02.122

9. Ruiz-Fernández, A.C., Sanchez-Cabeza, J. A., Pérez-Bernal, L. H., and Gracia, A. 2019. "Spatial and temporal distribution of heavy metal concentrations and enrichment in the southern Gulf of Mexico." Science of The Total Environment, 651, pp.3174-3186. https://doi.org/10.1016/j.scitotenv.2018.10.109

10. Modabberi, S., Tashakor, M., Sharifi Soltani, N., and Hursthouse, A. S. 2018. "Potentially toxic elements in urban soils: source apportionment and contamination assessment." Environmental Monitoring and Assessment, 190(12), pp.1-18. https://doi.org/10.1007/s10661-018-7066-8

11. Khademi, H., Gabarrón, M., Abbaspour, A., Martínez-Martínez, S, Faz, A., and Acosta, J. A. 2019. "Environmental impact assessment of industrial activities on heavy metals distribution in street dust and soil." Chemosphere, 217, pp.695-705. https://doi.org/10.1016/j.chemosphere.2018.11.045

12. Li, F., Zhang, J., Liu, W., Liu, J., Huang, J., and Zeng, G. 2018 "An exploration of an integrated stochastic-fuzzy pollution assessment for heavy metals in urban topsoil based on metal enrichment and bioaccessibility." Science of The Total Environment, 644, pp.649-660. https://doi.org/10.1016/j.scitotenv.2018.06.366

13. Kharazi, A., Leili, M., Khazaei, M., Alikhani, M. Y., and Shokoohi, R. 2021. "Human health risk assessment of heavy metals in agricultural soil and food crops in Hamadan, Iran." Journal of Food Composition and Analysis, 100, pp.103890. https://doi.org/10.1016/j.jfca.2021.103890

14. Liu, Z., Zhang, Q., Han, T., Ding, Y., Sun, J., Wang, F., andZhu C. 2015. "Heavy Metal Pollution in a Soil-Rice System in the Yangtze River Region of China." International Journal of Environmental Research and Public Health, 13(1), pp.63. https://doi.org/10.3390/ijerph13010063

15. Vesey, D. A. 2010. "Transport pathways for cadmium in the intestine and kidney proximal tubule: Focus on the interaction with essential metals." Toxicology Letters, 198(1), pp.13-19. https://doi.org/10.1016/j.toxlet.2010.05.004

16. Wang, B., Li, Y., Shao, C., Tan, Y., and Cai, L. 2012. "Cadmium and Its Epigenet ic Effects." Current Medicinal Chemistry, 19(16), pp.2611-2620. https://doi.org/10.2174/092986712800492913

17. He, Y., von Lampe, K., Wood, L., and Kurti, M. 2015. "Investigation of lead and cadmium in counterfeit cigarettes seized in the United States." Food and Chemical Toxicology, 81, pp.4045. https://doi.org/10.1016/j.fct.2015.04.006

18. Baş, H., Kalender, Y., Pandir, D., and Kalender, S. 2015. "Effects of lead nitrate and sodium selenite on DNA damage and oxidative stress in diabetic and non-diabetic rat erythrocytes and leucocytes.' Environmental Toxicology and Phamacology, 39(3), pp.10191026. https://doi.org/10.1016/j.etap.2015.03.012

19. Manjuladevi, M., Anitha, R., and Manonmani, S. 2018. "Kinetic study on adsorption of $\mathrm{Cr}(\mathrm{VI}), \mathrm{Ni}$ (II), $\mathrm{Cd}(\mathrm{II})$ and $\mathrm{Pb}$ (II) ions from aqueous solutions using activated carbon prepared from Cucumis melo peel." Applied Water Science, 8(1), pp.1-8. https://doi.org/10.1007/s13201-018-0674-1

20. Das, K. K., Reddy, R. C., Bagoji, I. B., Das, S., Bagali, S., Mullur, L., Khodnapur, J. P., and Biradar, M. S. 2019. "Primary concept of nickel toxicity - an overview." Journal of Basic and Clinical Physiology and Pharmacology, 30(2), pp.141-152. https://doi.org/10.1515/jbcpp-2017-0171

21. Agency for Toxic Substances and Disease Registry (ATSDR) 2012. "Toxicological profile for Vanadium", Atlanta, GA: U.S.
Department of Health and Human Services, Public Health Service.

22. Alsaleh, K. A. M., Meuser, H., Usman, A. R. A., Al-Wabel, M. I. and Al-Farraj, A. S. 2018. "A comparison of two digestion methods for assessing heavy metals level in urban soils influenced by mining and industrial activities." Journal of Environmental Management, 206, pp.731-739. https://doi.org/10.1016/j.jenvman.2017.11.026

23. Kumar, V., Sharma, A., Kaur, P., Singh Sidhu, G. P., Bali, A. S Bhardwaj, R., Thukral, A. K., and Cerda, A. 2019. "Pollution assessment of heavy metals in soils of India and ecological risk assessment: A state-of-the-art.” Chemosphere, 216, pp.449-462. https://doi.org/10.1016/j.chemosphere.2018.10.066

24. Wuana, R. A., and Okieimen, F. E. 2011. "Heavy Metals in Contaminated Soils: A Review of Sources, Chemistry, Risks and Best Available Strategies for Remediation.” ISRN Ecology, 2011, pp.1-20. https://doi.org/10.5402/2011/402647

25. Rastegari Mehr, M., Keshavarzi, B., Moore, F., Sharifi, R., Lahijanzadeh, A., and Kermani, M. 2017. "Distribution, source identification and health risk assessment of soil heavy metals in urban areas of Isfahan province, Iran.” Journal of African Earth Sciences, $132, \quad$ pp.16-26. https://doi.org/10.1016/j.jafrearsci.2017.04.026

26. Mazhari, S. A., Bajestani, A. R. M., Hatefi, F., Aliabadi, K., and Haghighi, F. 2018. "Soil geochemistry as a tool for the origin investigation and environmental evaluation of urban parks in Mashhad city, NE of Iran." Environmental Earth Sciences, 77(13), pp.1-17. https://doi.org/10.1007/s12665-018-7684-Z

27. Jiang, Y., Chao, S., Liu, J., Yang, Y., Chen, Y., Zhang, A., and Cao, H. 2017. "Source apportionment and health risk assessment of heavy metals in soil for a township in Jiangsu Province, China." Chemosphere, 168, pp.1658-1668. https://doi.org/10.1016/j.chemosphere.2016.11.088

28. Shehzad, M. T., Murtaza, G., Shafeeque, M., Sabir, M., Nawaz, H., and Khan, M. J. 2019. "Assessment of trace elements in urban topsoils of Rawalpindi-Pakistan: a principal component analysis approach." Environmental Monitoring and Assessment, 191(2), pp.65. https://doi.org/10.1007/s10661-019-7212-y

29. Kabata-Pendias, A. and Mukherjee, A.B. 2007. "Trace Elements from soil to Human", Springer Berlin Heidelberg New York.

30. AST M, 2000. “Annual book of ASTM Standards AST M", Vol:11. 01, pp. D1971-95. D-4691-96.

31. Hakanson, L. 1980. "An ecological risk index for aquatic pollution control.a sedimentological approach." Water Research, 14(8), pp.975-1001. https://doi.org/10.1016/0043-1354(80)90143-8

32. Luo, X., Yu, S., Zhu, Y., and Li, X. 2012. "Trace metal contamination in urban soils of China." Science of The Total Environment, 421-422, pp.17-30. https://doi.org/10.1016/j.scitotenv.2011.04.020

33. Muller, G., 1969. "Index of geoaccumulation in sediments of the Rhine River”. Geojournal, 2, pp.108-118.

34. Ghrefat, H. A., Abu-Rukah, Y., and Rosen, M. A. 2011. "Application of geoaccumulation index and enrichment factor for assessing metal contamination in the sediments of Kafrain Dam, Jordan." Environmental Monitoring and Assessment, 178(1-4), pp.95-109. https://doi.org/10.1007/s10661-010-1675-1

35. Bhagure, G. R., and Mirgane, S. R. 2011. "Heavy metal concentrations in groundwaters and soils of Thane Region of Maharashtra, India." Environmental Monitoring and Assessment 173(1-4), pp.643-652. https://doi.org/10.1007/s10661-010-1412-9

36. Yu, D., Walters, D. M., Zhu, L., Lee, P.-K., and Chen, Y. 2011. "Vanadium pentoxide (V 2 O 5 ) induced mucin production by airway epithelium." American Journal of Physiology-Lung Cellular and Molecular Physiology, 301(1), pp.L31-L39. https://doi.org/10.1152/ajplung.00301.2010

37. Amouei, A., Cherati, A., and Naghipour, D. 2017. "Heavy Metals Contamination and Risk Assessment of Surface Soils of Babol in Northern Iran." Health Scope, 7(1). 
https://doi.org/10.5812/jhealthscope.62423

38. Amjadian, K., Sacchi, E., and Rastegari Mehr, M. 2016. "Heavy metals (HMs) and polycyclic aromatic hydrocarbons (PAHs) in soils of different land uses in Erbil metropolis, Kurdistan Region, Iraq." Environmental Monitoring and Assessment, 188(11), pp.605. https://doi.org/10.1007/s10661-016-5623-6

39. Jorfi, S., Maleki, R., Jaafarzadeh, N., and Ahmadi, M. 2017 "Pollution load index for heavy metals in Mian-Ab plain soil, Khuzestan, Iran." Data in Brief, 15, pp.584-590. https://doi.org/10.1016/j.dib.2017.10.017

40. Ahmadi Doabi, S., Karami, M., and Afyuni, M. 2019. "Heavy metal pollution assessment in agricultural soils of Kermanshah province, Iran." Environmental Earth Sciences, 78(3), pp.70. https://doi.org/10.1007/s12665-019-8093-7

41. Manta, D. S., Angelone, M., Bellanca, A., Neri, R., and Sprovieri, M. 2002. "Heavy metals in urban soils: a case study from the city of Palermo (Sicily), Italy." Science of The Total Environment, 300(1-3), pp.229-243. https://doi.org/10.1016/S00489697(02)00273-5

42. Dhaliwal, S. S., Setia, R., Kumar, V., Ghosh, T., Taneja, S., Singh, R., Ansari, J., Kukal, S. S., and Pateriya, B. 2021 . "Assessment of seasonal variations and human health risks due to heavy metals in water, soils and food crops using multi-indices approach." Environmental Earth Sciences, 80(11), pp.411. https://doi.org/10.1007/s12665-021-09686-4

43. Ahmadi, M., Jorfi, S., Azarmansuri, A., Jaafarzadeh, N., Mahvi, A. H., Darvishi Cheshmeh Soltani, R., Akbari, H., and Akhbarizadeh, R. 2017. "Zoning of heavy metal concentrations including $\mathrm{Cd} \mathrm{Pb}$ and As in agricultural soils of Aghili plain, Khuzestan province, Iran." Data in Brief, 14, pp.20-27. https://doi.org/10.1016/j.dib.2017.07.008

44. Ahmadi Doabi, S., Karami, M., and Afyuni, M. 2016. "Regionalscale fluxes of zinc, copper, and nickel into and out of the agricultural soils of the Kermanshah province in western Iran." Environmental Monitoring and Assessment, 188(4), pp.216. https://doi.org/10.1007/s10661-016-5225-3

45. Yahaya, S. M., Abubakar, F., and Abdu, N. 2021. "Ecological risk assessment of heavy metal-contaminated soils of selected villages in Zamfara State, Nigeria." SN Applied Sciences, 3(2), pp.168. https://doi.org/10.1007/s42452-021-04175-6

46. Hafezi Moghaddas, N., Hajizadeh Namaghi, H., Ghorbani, H., and Dahrazma, B. 2013. "The effects of agricultural practice and landuse on the distribution and origin of some potentially toxic metals in the soils of Golestan province, Iran." Environmental Eanth Sciences, 68(2), pp.487-497. https://doi.org/10.1007/s12665-0121753-5

47. Jia, Z., Li, S., and Wang, L. 2018. “Assessment of soil heavy metals for eco-environment and human health in a rapidly urbanization area of the upper Yangtze Basin.” Scientific Reports, 8(1), pp.3256. https://doi.org/10.1038/s41598-018-21569-6

48. Adedeji, O. H., Olayinka, O. O., and Tope-Ajayi, O. O. 2019 "Spatial Distribution and Health Risk Assessment of Soil Pollution by Heavy Metals in Ijebu-Ode, Nigeria." Journal of Health and Pollution, 9(22), pp.190601. https://doi.org/10.5696/2156-96149.22.190601

49. Adesuyi, A. A., Njoku, K. L., and Akinola, M. O. 2015. "Assessment of Heavy Metals Pollution in Soils and Vegetation around Selected Industries in Lagos State, Nigeria." Journal of Geoscience and Environment Protection, 03(07), pp.11-19. https://doi.org/10.4236/gep.2015.37002

50. Fonge, B. A., Larissa, M. T., Egbe, A. M., Afanga, Y. A., Fru, N. G., and Ngole-Jeme, V. M. 2021. "An assessment of heavy metal exposure risk associated with consumption of cabbage and carrot grown in a tropical Savannah region." Sustainable Environment, 7(1), pp.1909860. https://doi.org/10.1080/27658511.2021.1909860

\section{COPYRIGHTS}

(C2021 The author(s). This is an open access article distributed under the terms of the Creative Commons Attribution (CC BY 4.0), which permits unrestricted use, distribution, and reproduction in any medium, as long as the original authors and source are cited. No permission is required from the authors or the publishers.
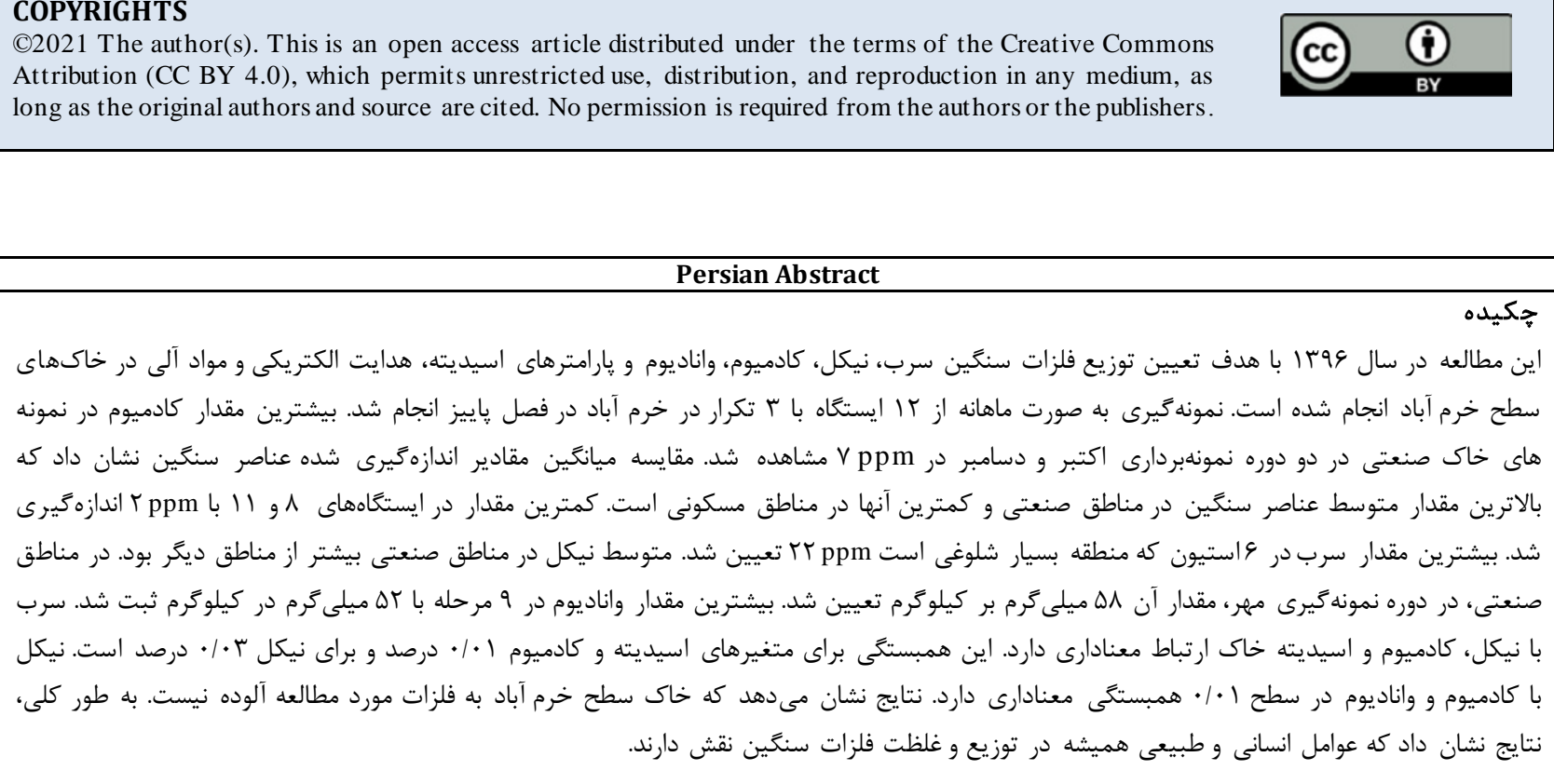